\title{
Symptoms and quality of life in heart failure: the muscle hypothesis
}

\author{
Andrew J S Coats, Andrew L Clark, Massimo Piepoli, Maurizio Volterrani, \\ Philip A Poole-Wilson
}

National Heart and Lung Institute and Royal Brompton National Heart and Lung Hospital, London A J S Coats A L Clark M Piepoli $M$ Volterrani P A Poole-Wilson

Correspondence to: Dr A J S Coats, National Heart and Lung Institute, Dovehouse Street, London SW3 6LY.
Heart failure is a common and debilitating condition with a high mortality. ${ }^{1}$ Reductions in mortality in this condition have been achieved by treatment with vasodilators, in particular the angiotensin converting enzyme (ACE) inhibitors, but there remains a considerable burden of disability and mortality. The other mainstay, diuretic treatment, has never been shown to reduce mortality in heart failure but its ability to relieve life threatening pulmonary oedema and to help relieve fluid retention and dyspnoea in chronic heart failure is not seriously questioned.

It is likely to be increasingly difficult to reduce mortality with newer treatments without specifically targeting the underlying processes leading to left ventricular dysfunction. There remain, however, many unrelieved symptoms in optimally treated patients, with a correspondingly low quality of life. This is a valid area for therapeutic intervention, but one in which objective measurements of benefit have proved difficult to obtain. Therapeutic strategies have also been limited by our poor understanding of the physiological bases of the cardinal symptoms, dyspnoea and fatigue.

\section{Measurement of quality of life in heart failure}

Fletcher and colleagues have described the requirements of an ideal assessment of the quality of life (table). ${ }^{2}$ Questionnaires are the most common means of achieving such an assessment, and these can take the form of a general health survey-for example, the Nottingham health profile ${ }^{3}$-or be specific to the condition under investigation-for example, the Yale scale, ${ }^{4}$ or the Minnesota living with heart failure questionnaire. ${ }^{5}$ Quality of

Steps to ensure maximum information from quality of life analyses

Scoring

Use conventional methods

Keep weightings simple or avoid if possible Analyse sensitivity

Multidimensional issues

Specify key variables before starting study

Analyse each dimension separately

Test for treatment-dimension interactions

Withdrawal of patients

All subjects should complete quality of life assessments at withdrawal

Analyse quality of life and survival separately

Clinically important effects

Reproduced with permission. ${ }^{2}$ life assessments have indicated improvement with some treatments, but on an individual patient basis there can be very poor correlation between the change in the quality of life scores and objective improvements in exercise tolerance. Also, different exercise protocols can show different changes with intervention, and there is little consensus as to whether incremental exercise tests or submaximal endurance tests better measure the symptoms limiting patients with chronic heart failure. ${ }^{6}$

\section{Symptoms limiting exercise in chronic} heart failure

There is little correlation at rest or during exercise between measures of haemodynamics and either the symptoms limiting exercise in chronic heart failure or the degree of such limitation. Different symptoms may be produced by different forms of exercise tests or by different speeds of incremental exercise tests. ${ }^{7}$ Even in the same patient there is little correlation between the peak achieved pulmonary artery pressure and which of the two main symptoms limit different types of exercise. ${ }^{7}$ With ambulatory pulmonary arterial pressure monitoring it has been shown that limiting dyspnoea can occur at dramatically different peak pulmonary arterial pressures during different types of exercise. ${ }^{8}$ This argues against pulmonary arterial haemodynamics being the main determinant of this symptom.

The inability of haemodynamics to explain the generation of symptoms in chronic heart failure calls into question the dependence that has traditionally been placed on haemodynamic screens for potential agents of heart failure. If non-haemodynamic peripheral factors both limit exercise and are responsible for generation of symptoms, then other nonhaemodynamic modes of action may be effective for relief of symptoms in chronic heart failure.

\section{Muscle fatigue in chronic heart failure}

Muscle fatigue can arise due to alterations in the supply of oxygen to exercising muscle or to a change in the muscle itself. Skeletal muscle can be abnormal in terms of total mass, structure, or metabolic or contractile function. Although restrictions in peak blood flow to exercising muscle have been shown in heart failure, ${ }^{910}$ it is not clear to what extent this is due to persistent vasoconstrictor drive, impaired endothelial dependent vasodilator function, or a reduction in either muscle capil- 


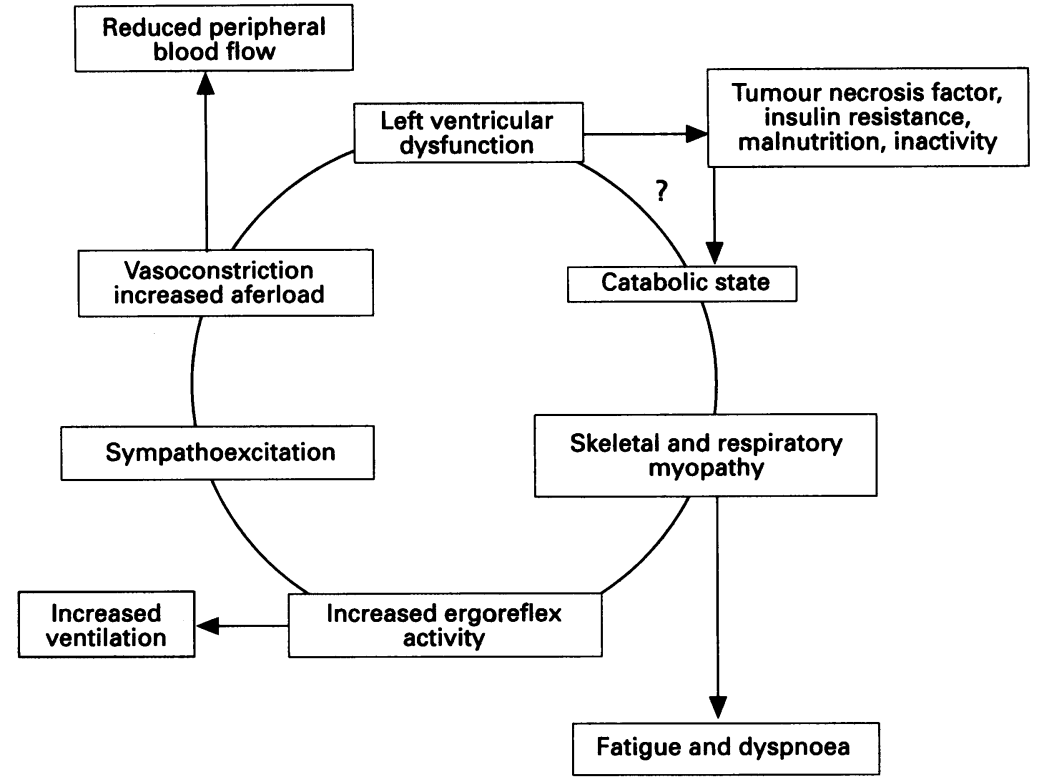

Figure 1 The muscle hypothesis of chronic heart failure. In this hypothesis an initial reduction in left ventricular function activates catabolic and reduces anabolic factors that cause skeletal myopathy. This in turn leads to exercise intolerance and sympathoexcitation that, through the combined effects of a persistent catabolic state and of profound inactivity, further worsen skeletal muscle structure and function, and may eventually lead to a progressive effect on remodelling of the left ventricle. muscle wasting. These structural and metabolic changes in skeletal muscle could also explain the delay in improvement in symptoms and exercise tolerance after effective haemodynamic improvement with ACE inhibitors ${ }^{17}$ or even cardiac transplantation. ${ }^{18}$

\section{Dyspnoea in chronic heart failure}

Dyspnoea is a difficult sensation to quantify and even more difficult to explain. ${ }^{19}$ There is a fairly close relation between the perception of dyspnoea and minute ventilation, perhaps through a perception of the respiratory effort required to generate and maintain a certain level of ventilation during exercise. There may also be a direct appreciation of the chemoreceptor drive to breathing or of the level of respiratory stimulating factors such as arterial lactate, $\mathrm{pH}$, potassium, adenosine, carbon dioxide, and other unknown factors.

The normal mechanisms whereby ventilatory effort is matched to muscular work are imperfectly understood. Even less is known of the pathophysiology that produces both an excessive sensation of breathlessness and an exaggerated ventilatory response in heart failure. ${ }^{20}$ It has been argued that the increased ventilation seen during exercise in patients with heart failure must indicate the presence of wasted ventilation in the form of dead space ventilation because there is no substantial fall in arterial blood concentrations of $\mathrm{CO}_{2}$. There is, however, often a modest fall in arterial $\mathrm{CO}_{2}$ during exercise, and arterial $\mathrm{O}_{2}$ rarely if ever falls in stable heart failure, so the factor that initiates and maintains the increased ventilatory response is not obvious. Something other than $\mathrm{CO}_{2}$ retention or hypoxia must be driving both the sensation of breathlessness and the resultant exaggerated ventilatory response. We have studied this response by looking at the ventilatory equivalent for $\mathrm{CO}_{2}$ (the slope between ventilation and the rate of $\mathrm{CO}_{2}$ production) during exercise. ${ }^{21}$ This slope is increased in heart failure and the increase in slope correlates well with the severity of heart failure as assessed by peak $\mathrm{O}_{2}$ consumption (fig 2 ).

It is not known which of several independent and complementary ventilatory control systems can account for the increased ventilation in heart failure, but early lactic acid release and acidosis, potassium release, respiratory muscle fatigue, non-asthmatic bronchial constriction, and a muscle ergoreflex $^{22}$ have all been proposed. Circulating factors including lactate and acidosis do not seem necessary for this response and differences in potassium release do not seem to account for the altered response in heart failure (unpublished observations).

The frequent coexistence of dyspnoea and fatigue and the delay in resolution of dyspnoea after haemodynamic improvement raise the possibility that structural abnormalities of skeletal muscle may be involved in the generation of dyspnoea. Dyspnoea and increased ventilation could be manifestations of abnormalities in respiratory musculature similar to 
those seen in skeletal muscle. Early respiratory muscle fatigue and histological changes in the diaphragm ${ }^{23}$ have been seen in chronic heart failure. An alternative explanation is that skeletal muscle signals contribute directly to the perception of both muscle fatigue and dyspnoea, not only through the excessive release of blood borne metabolic factors, but possibly also through an exaggerated neural signal from the muscle.

\section{Mechanisms of skeletal myopathy in chronic heart failure}

The cause of the changes in skeletal muscle in chronic heart failure is not clear, but research on the beneficial effects of exercise training on skeletal muscle function in heart failure ${ }^{24-26}$ has suggested that inactivity may play a part. Metabolic or hormonal derangements that favour catabolism over anabolism may also contribute to the myopathy. Possibilities include the release of tumour necrosis factor, abnormalities in the handling of intracellular thyroid hormone, and insulin resistance, as well as intestinal malabsorption. There is little agreement as to whether chronically impaired skeletal muscle flow is an important cause of the myopathy of heart failure, but the dissimilarity between the muscle changes of heart failure and the increased oxidative capacity seen in patients with peripheral vascular insufficiency make this unlikely. Similar changes are by contrast seen in chronic lung disease suggesting that many chronic disease processes involving prolonged inactivity may lead to a similar syndrome. ${ }^{27}$ The cachexia of neoplastic disease has some similarities with cardiac cachexia, and this syndrome can also be associated with unexplained dyspnoea.

Importance of skeletal myopathy in heart failure: the skeletal muscle ergoreflex Small myelinated and unmyelinated fibres arise from poorly characterised work sensitive receptors within skeletal muscle. ${ }^{28}$ These fibres travel in the lateral spinothalamic tract and have been shown to mediate an ergoreflex effect constituting an increase in sympathetic outflow producing vasoconstriction in distant vascular beds and possibly a small increase in heart rate. ${ }^{28}$ They are sensitive to the metabolic state of the muscle but not to ischaemia alone; rather they are work sensors. Excess of intramuscular potassium may stimulate their activation. We have recently shown that these ergoreceptors are active in patients with heart failure and that they also substantially contribute to the ventilatory response to exercise in both normal people and patients with heart failure. ${ }^{22}$ Also they are ideal candidate receptors for the perception of muscular fatigue and that component of dyspnoea that cannot be explained by circulating metabolites.

Although one short report suggested that the sympathetic nervous response to ergoreceptor activation in heart failure was blunted, the vastly different baseline levels of sympathetic tone in the two patient groups in this paper made it difficult to interpret the incremental effect of ergoreflex activation. ${ }^{29}$ The muscle ergoreceptors have the properties necessary to link the abnormal skeletal muscle function of chronic heart failure to the fatigue, dyspnoea, hyperpnoea, and sympathoexcitation characteristic of this condition.

\section{The muscle hypothesis of chronic heart} failure

We propose that abnormal skeletal muscle in chronic heart failure is a central abnormality that can account for much of the pathophysiology and symptoms of the condition. This hypothesis proposes another cycle of deterioration similar to those of neuroendocrine activation. A reduction in left ventricular function sets in motion a series of metabolic events that lead to wasting of skeletal muscle and resultant abnormalities of muscular metabolism and function. In response to early metabolic distress in exercising muscle an exaggerated ergoreflex activation occurs that is perceived by the patient as both muscle fatigue and dyspnoea. This leads to excessive reflex sympathetic vasoconstrictor drive to non-exercising muscle beds and an excessive ventilatory response to exercise. Resolution of these symptoms and the exaggerated reflex responses would depend on resolution of the abnormal function of skeletal muscle, and would, therefore, be delayed after haemodynamic correction and would be most noticeable in treatments associated with a specific improvement in muscle function or exercise responses. Figure 1 shows the proposed sequence of events.

Consequences of a muscle hypothesis for the generation of symptoms in heart failure

Valid areas for investigation (and perhaps intervention) exist to prevent the cycle of events described in this hypothesis. One aspect of this theory is that the skeletal myopathy, by exaggerating the sympathetic nervous responses to exercise, may actually contribute to the progression of the disease process through an exaggeration of peripheral vasoconstriction and hence the afterload that develops and through the direct myotoxic effects of prolonged sympathoexcitation. Ventricular remodelling and the propensity to ventricular arrhythmias are both thought to be partly a result of such excessive and prolonged sympathetic activation. The precise mechanism of the persistent sympathoexcitation of chronic heart failure has never been established. The arterial baroreflex loop is not an ideal explanation because the gain of this reflex is known to be dramatically impaired in heart failure,,$^{30} 31$ and hence it would be unable to respond acutely by increasing sympathetic outflow. Impaired baroreflex activity would also not lead to such a degree of sympathetic activation. Other putative mechanisms such as activation of the renal renin-angiotensin system, low pressure receptors, cardiocardiac 
reflexes, or intracranial pressure flow autoregulation cannot adequately explain the maintenance and progression of sympathetic activation. The ergoreflex given its sympathoexcitatory role when muscle physiology is perturbed may play an important part in this activation. Once activated, sympathetic tone may contribute to further catabolism of skeletal muscle and a progression of the deleterious cycle.

\section{Improving symptoms in chronic heart failure}

As we know so little of the genesis of the limiting symptoms in chronic heart failure, it is perhaps not surprising that we cannot accurately predict which treatments will improve symptoms in this condition. There can be dramatic discrepancies between haemodynamic effects, exercise indices, and quality of life scores. Only a more detailed understanding of the integrated pathophysiology underlying both the progression of the disease and the complex interaction between exercise responses and symptoms can allow more effective treatments to be designed. To do this we may have to look beyond the conventional haemodynamic remedies for heart failure. The benefits of exercise training on skeletal muscle structure and function and the parallel reduction in dyspnoea, ventilatory abnormalities, and sympathetic overactivity ${ }^{32}$ suggest that specific muscle treatments may help in the management of chronic heart failure.

1 Poole-Wilson PA. Chronic heart failure: causes, pathophysiology, prognosis, clinical manifestations, investigaphysiology, prognosis, clinical manifestations, investigations. In: Diseases of the heart. Poole-W

2 Fletcher AE, Hunt BM, Bulpitt CJ. Evaluation of quality of life in clinical trials of cardiovascular disease. $\mathcal{f}$ Chron Dis 1987; 40:557-66.

3 Hunt SM, McKenna SP, McEwen J. A quantitative approach to perceived health. $\mathcal{F}$ Epidemiol Community Health 1980;34:282-5.

4 Feinstein AR, Fisher MB, Pigeon JG. Changes in dyspneafatigue ratings as indicators of quality of life in the treatment of congestive heart failure. $A m f$ Cardiol 1989;64:50-5.

5 Rector TS, Kubo SH, Cohn JN. Patients self-assessment of their congestive heart failure. Heart Failure 1987;1:198-209.

6 Cowley AJ, Fullwood L, Stainer K, Hampton JR. Exercise tolerance in patients with heart failure-how should it be tolerance in patients with heart failure

7 Lipkin DP, Canepa-Anson R, Stephens MR, PooleWilson PA. Factors determining symptoms in heart failure: comparison of fast and slow exercise tests. Br Heart $\mathcal{F}$ ure: comparison of

8 Gibbs JSR, Keegan J, Wright C, Fox KM, Poole-Wilson PA. Pulmonary artery pressure changes during exercise and daily activities in chronic heart failure. $\mathscr{f} \mathrm{Am} \mathrm{Coll}$ Cardiol 1990;15:52-61.
9 Wilson JR, Wiener DH, Fink LI, Ferraro N. Vasodilatory behavior of skeletal muscle arterioles in patients with nonedematous chronic heart failure. Circulation 1986;74:775-9.

10 Zelis R, Nellis SH, Longhurst J, Lee G, Mason DT Abnormalities in the regional circulations accompanying congestive heart failure. Prog Cardiovasc Dis 1975;18:181-99.

11 Lipkin DP, Jones DA, Round JM, Poole-Wilson PA Abnormalities of skeletal muscle in patients with chronic Abnormalities of skeletal muscle in patients

12 Drexler H, Riede U, Münzel T, König H, Funke E, Just H. Alterations of skeletal muscle in chronic heart failure. Circulation 1992;85:1751-9.

13 Sullivan MJ, Green HJ, Cobb FR. Skeletal muscle biochemistry and histology in ambulatory patients with long-term heart failure. Circulation 1990;81:518-27.

14 Massie B, Conway M, Yonge R, et al. Skeletal muscle metabolism in patients with congestive heart failure: relation to clinical severity and blood flow. Circulation 1987;76:1009-19.

15 Buller NP, Jones D, Poole-Wilson PA. Direct measurement of skeletal muscle fatigue in patients with chronic heart failure. Br Heart $f$ 1991;65:20-4.

16 Volterrani M, Clark AL, Ludman PF, Swan J, Coats AJS Muscle wasting is a determinant of maximal oxygen consumption in patients with chronic heart failure [abstract]. Eur Heart $f$ 1993;14(suppl):338.

17 Drexler $H$, Banhardt U, Meinertz T, Wollschläger $H$ Lehmann $\mathbf{M}$, Just $\mathrm{H}$. Contrasting peripheral short-term and long-term effects of converting enzyme inhibition in patients with congestive heart failure. A double-blind placebo-controlled trial. Circulation 1989;79:491-502.

18 Sinoway L, Minotti JR, Davis D, Pennock JL, Burg JE, Musch TI. Delayed reversal of impaired vasodilatation in congestive heart failure after heart transplantation. Am F Cardiol 1988;61:1076-9.

19 Stark RD. Dyspnoea: assessment and pharmacological manipulation. Eur Respir ₹ 1988;1:280-7.

20 Clark A, Coats A. The mechanisms underlying the increased ventilatory response to exercise in chronic stable increased ventilatory response to exercise in ch

21 Buller NP, Poole-Wilson PA. Mechanism of the increased ventilatory response to exercise in patients with chronic ventilatory response to exercise in patie

22 Piepoli M, Coats AJS. Skeletal muscle ergoreflex: a possible role in the ventilatory control [abstract]. Circulation 1992;86(suppl I):1-368.

23 Lindsay DC, Lovegrove CA, Dunn MJ, Bennett JG Pepper JR, Yacoub MH, Poole-Wilson PA. Histologica abnormalities of diaphragmmatic muscle may contribute to dyspnoea in heart failure. Circulation 1992;86(supp I): $1-514$.

24 Minotti JR, Johnson EC, Hudson TL, et al. Skeletal muscle response to exercise training in congestive heart failure. $\mathcal{F}$ Clin Invest 1990;86:751-8.

25 Adamopoulos S, Coats AJ, Brunotte F, et al. Physical training improves skeletal muscle metabolism in patients with chronic heart failure. $f$ Am Coll Cardiol with chronic 6 ; 21 :1101-6.

26 Adamopoulos S, Brunotte F, Coats A, et al. Skeletal muscle metabolism in experimental heart failure: effects of infarct size and physical training [abstract]. $\mathcal{f} \mathrm{Am} \mathrm{Coll}$ Cardiol 1992;17(suppl A):158A.

27 Tada $\mathrm{H}$, Kato $\mathrm{H}$, Misawa $\mathrm{T}$, et al. 31P-nuclear magnetic resonance evidence of abnormal skeletal muscle metabolism in patients with chronic lung disease and congestive heart failure [see comments]. Eur Respir ₹ 1992;5:163-9.

28 Liang C-S, Hood WBJr. Afferent neural pathway in the regulation of cardiopulmonary responses to tissue hypermetabolism. Cir Res 1976;38:209-14.

29 Sterns DA, Ettinger SM, Gray KS, et al. Skeletal muscle metaboreceptor exercise responses are attenuated in heart failure. Circulation 1991;84:2034-9.

30 Mohanty PK, Thames MD, Arrowood JA, Sowers JR McNamara C, Szentpetery S. Impairment of cardiopulmonary baroreflex after cardiac transplantation in monary baroreflex after cardiac

31 Smith ML, Ellenbogen KA, Eckberg DL, Szentpetery S, Thames MD. Subnormal heart period variability in heart failure: effect of cardiac transplantation. $\Im \mathrm{Am}$ Coll Cardiol 1989;14:106-11.

32 Coats AJS, Adamopoulos S, Radaelli A, McCance A Meyer TE, Bernardi L, et al. Controlled trial of physica training in chronic heart failure: exercise performance, hemodynamics, ventilation and autonomic function. Circulation 1992;85:2119-31. 